\title{
Mapping areas invaded by Prosopis juliflora in Somaliland on Landsat 8 imagery
}

Felix Rembold, Ugo Leonardi, Wai-Tim Ng, Hussein Gadain, Michele Meroni, et al.

Felix Rembold, Ugo Leonardi, Wai-Tim Ng, Hussein Gadain, Michele Meroni, Clement Atzberger, "Mapping areas invaded by Prosopis juliflora in Somaliland on Landsat 8 imagery," Proc. SPIE 9637, Remote Sensing for Agriculture, Ecosystems, and Hydrology XVII, 963723 (14 October 2015); doi: 10.1117/12.2193133

SPIE. Event: SPIE Remote Sensing, 2015, Toulouse, France 


\title{
Mapping areas invaded by Prosopis juliflora in Somaliland with Landsat 8 imagery
}

\author{
Felix Rembold*a, Ugo Leonardi ${ }^{\mathrm{b}}$, Wai-Tim $\mathrm{Ng}^{\mathrm{c}}$, Hussein Gadain ${ }^{\mathrm{b}}$, Michele Meroni ${ }^{\mathrm{a}}$, Clement \\ Atzberger $^{\mathrm{C}}$ \\ ${ }^{a}$ Joint Research Center of the European Commission, MARS Unit, Via Fermi 2749, TP. 266, 21027 \\ Ispra (VA), Italy; ${ }^{\mathrm{b}}$ Food and Agriculture Organization of the United Nations, Somalia Water and \\ Land Information Management (FAO-SWALIM) Project, P. O. Box 30470-00100 Nairobi, Kenya; \\ 'Institute for Surveying, Remote Sensing and Land Information, University of Natural Resources \\ and Life Sciences (BOKU), Vienna, Peter Jordan Straße 82, A-1190 Vienna, Austria
}

\begin{abstract}
Prosopis juliflora is a fast growing tree species originating from South and Central America with a high invasion potential in semi-arid areas around the globe. It was introduced to East Africa for the stabilization of dune systems and for providing fuel wood after prolonged droughts and deforestation in the 1970s and 1980s. In many dry lands in East Africa the species has expanded rapidly and has become challenging to control. The species generally starts its colonization on deep soils with high water availability while in later stages or on poorer soils, its thorny thickets expand into drier grasslands and rangelands. Abandoned or low input farmland is also highly susceptible for invasion as $P$. juliflora has competitive advantages to native species and is extremely drought tolerant.

In this work we describe a rapid approach to detect and map P. juliflora invasion at country level for the whole of Somaliland. Field observations were used to delineate training sites for a supervised classification of Landsat 8 imagery collected during the driest period of the year (i.e., from late February to early April). The choice of such a period allowed to maximise the spectral differences between $P$. juliflora and other species present in the area, as $P$. juliflora tends to maintain a higher vigour and canopy water content than native vegetation, when exposed to water stress.

The results of our classification map the current status of invasion of Prosopis in Somaliland showing where the plant is invading natural vegetation or agricultural areas. These results have been verified for two spatial subsets of the whole study area with very high resolution (VHR) imagery, proving that Landsat 8 imagery is highly adequate to map $P$. juliflora. The produced map represents a baseline for understanding spatial distribution of $P$. juliflora across Somaliland but also for change detection and monitoring of long term dynamics in support to P. juliflora management and control activities.
\end{abstract}

Keywords: Remote sensing, Prosopis juliflora, invasive species, Somaliland

\section{INTRODUCTION}

Prosopis juliflora was initially introduced to East Africa as ecosystem engineer for the stabilization of dune systems, habilitation of degraded land ${ }^{1}$ and for providing fuel wood ${ }^{2,3}$. However, in many areas the species is rapidly expanding and aggressively outcompeting native shrub and tree vegetation ${ }^{1}$. In Somalia it was used from the 1970s for sand dune fixation in central regions and close to Mogadischu ${ }^{4}$. While it was introduced in Somaliland in the late '70s by the Food and Agriculture Organization (FAO) and in the ' 80 s by several NGOs as fast growing tree species in areas that had been deforested by refugees ${ }^{5}$. Since then it has spread vigorously and is becoming a common presence in every major village in the country across many different landscapes. Managing its use and expansion properly is increasingly challenging and bulldozers are commonly applied to clear plots in the peri-urban areas of the capital, Hargeisa. In neighbouring Ethiopia it was planted in many arid and semi-arid regions mainly for soil and water conservation purposes ${ }^{6}$ and has become highly invasive in the 2000s as for example in the Baduu area of the Awash Basin ${ }^{7,8}$. In Kenya it is causing problems to natural vegetation and to pastoralists in the Turkana region, along the Tana river and in the Lake Baringo area $^{9}$; However, P. Juliflora is rapidly spreading also in other dryland areas.

Remote Sensing for Agriculture, Ecosystems, and Hydrology XVII, edited by

Christopher M. U. Neale, Antonino Maltese, Proc. of SPIE Vol. 9637, 963723

(C) 2015 SPIE · CCC code: $0277-786 X / 15 / \$ 18 \cdot$ doi: $10.1117 / 12.2193133$ 
P. juliflora typically initiates its invasion by transportation of seeds along watercourses and through animal dispersal, replacing endemic riverine plant communities ${ }^{1}$. After the initial establishment and with growing distance from deep soils with high water availability, thorny thickets invade native grasslands and rangelands. Abandoned and poorly productive farms are also highly susceptible for invasion as $P$. juliflora has competitive advantages on nutrients limited soils and is extremely drought tolerant thanks to its deep root system.

The ecological and socio-economic impacts of $P$. juliflora in Kenya and Somalia are vast and of various nature ${ }^{10}$. The palatable seed pods offer fodder for livestock, wild animals and can be used for human consumption, but both leaves and pods contain several toxins. The sweet pods can cause tooth decay for both cattle and goats when used as main fodder over long periods ${ }^{11}$. P. juliflora wood can be used for production of charcoal of comparable quality to Acacia species ${ }^{12}$, however the commonly found nearly impenetrable dense thickets do not produce much timber or fuel wood and are considered as breeding ground for malaria transmitting mosquitos ${ }^{9}$. Reports suggest that $P$. juliflora alters the ground water table ${ }^{13}$ and rapidly invades communal pastoral areas, while its thorns can cause injuries to humans and cattle and are known to puncture tires ${ }^{9}$. It is therefore necessary to carefully balance the advantages of $P$. juliflora use against the negative side effects and the risk of the plant expansion getting out of control. This risk is generally high in East Africa in all situations where $P$. juliflora is not carefully managed ${ }^{8}$.

Large parts of semi-arid areas in Eastern Africa are reportedly invaded by P. juliflora and the expansion is rapidly increasing especially in communal grazing areas ${ }^{10}$. The plant is also well visible on Google Earth type high resolution images for hotspots such as Hargeisa as well as the main coastal towns. Despite the extensive impact of $P$. juliflora on ecosystems and livelihoods, methods for assessing its distribution are scarcely developed. Most previous studies mapping P. juliflora in East Africa refer to the district or county level ${ }^{9,10}$ while approaches covering larger areas and based on multi-resolution satellite images have been tested only in South Africa ${ }^{14}$.

The objective of this study is to present a rapid and robust methodology for mapping $P$. juliflora across large areas at an acceptable spatial resolution. For mapping $P$. juliflora at the regional scale the study follows an approach which uses the full spectral information of Landsat- 8 imagery, by using a supervised classification of the original bands in the visible to mid infrared, as well as Normalized Difference Vegetation Index (NDVI).

Van den Berg et al. ${ }^{14}$ used a combination of terrain analysis and remote sensing techniques to map and monitor $P$. juliflora invasion of the Northern Province in Southern Africa. However, their remote sensing analysis was limited to simple thresholding of the near infrared/red band ratio during the greenest period of the year. As a result, $P$. juliflora was often confused with other bush and tree species. To map P. juliflora in semi-arid areas in Sudan, Hoshino et al. ${ }^{15}$ used a single threshold of the Normalized Difference Infrared Index (NDII) on Landsat imagery acquired during a drought period, but only in limited riverine areas. Classification approaches for $P$. juliflora mapping had already been adopted by Mohamed et al. ${ }^{16}$ and Mirik and Ansley ${ }^{17}$, who used different supervised classification techniques on multi-resolution satellite data, including Landsat imagery. However, these works focused on relatively small study areas. Ayanu et al. ${ }^{8}$ applied multi-temporal supervised classification on a combination of Landsat and Aster images, however in a very specific way for a flood plain ecosystem significantly smaller than the one targeted in the present study. In addition, the previous studies made no differentiation between mixed classes of $P$. juliflora and natural vegetation or $P$. juliflora and agriculture, albeit these are often the most commonly found situations on the ground.

\section{STUDY AREA}

Somaliland covers an area of $170,826 \mathrm{~km}^{2}$ and is characterized by a semi-arid and arid climate. Rainfall ranges from 50 to $150 \mathrm{~mm}$ and is mostly concentrated in the rainy period between April and June (Figure 1). The main land use is pastoral mostly nomadic or semi-nomadic. The primary livestock species are camels, goats, sheep and to a lesser extent cattle in the northern part of the study area. According to a recent study carried out by the Food and Agriculture Organization (FAO) Somalia Water and Land Information Management (SWALIM) in $2013^{18}$ based on visual interpretation of sample points on satellite imagery (Fig. 2), irrigated crops cover $620 \mathrm{~km}^{2}$, while the area covered by rain-fed crops is $2,268 \mathrm{~km}^{2}$. Irrigated agriculture is either located next to wadis (an Arabic term generally referring to semi-arid valleys often implying to dry riverbeds, containing water only during short periods of the year) and canals or makes use of ground water. The principal grain crop grown under rain-fed conditions is sorghum, followed by maize. Both crops are grown primarily for household consumption by small-scale farmers. Fruit and vegetable crops, which occupy relatively small areas, are grown mainly for commercial purposes. The sector is dominated by smallholder farmers who own farms ranging from 2 to 30 hectares, while the average farm size is approximately 4 hectares ${ }^{19}$. 
Many pastoral areas are threatened by land degradation due to overgrazing and soil erosion caused by vegetation cover $\operatorname{loss}^{20}$. Charcoal burning is carried out in the study area as an economic activity and severely affects very fragile ecosystems such as the tiger-bush areas ${ }^{21}$ by reducing biomass and further accelerating land degradation.

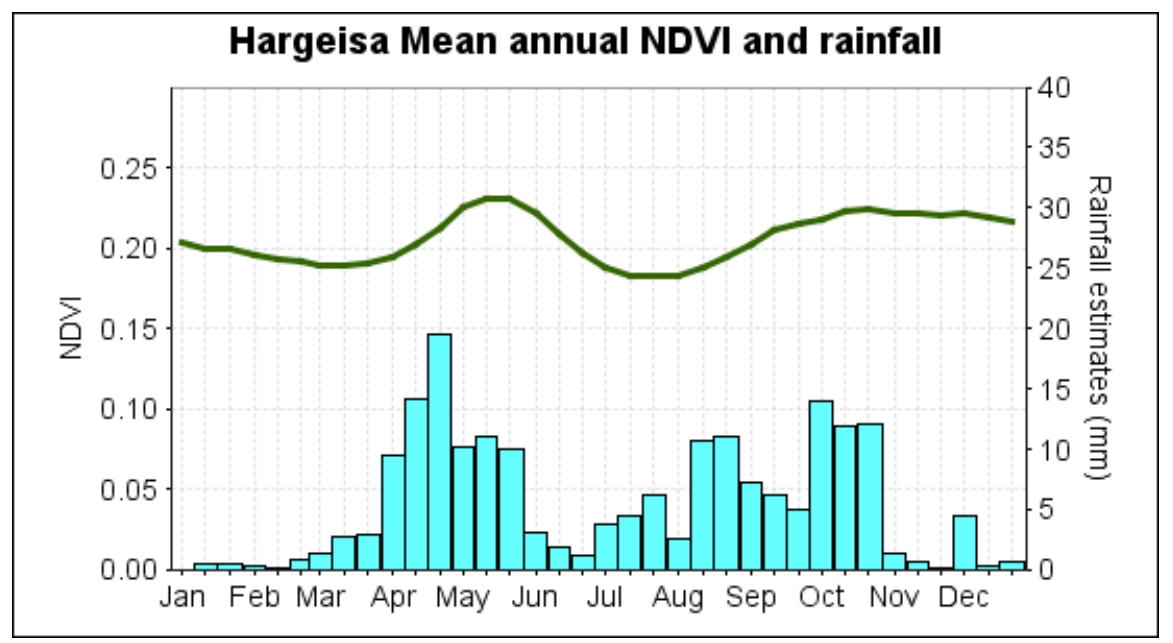

Figure 1. mean seasonal rainfall (mean rainfall estimates from TAMSAT) and vegetation activity (mean NDVI from SPOTVEGETATION) for the period 1999-2014 for the Hargeisa district showing the bimodal rainfall distribution and the long dry period from December to February.

P. juliflora is a constant presence in Somaliland's landscape since at least the 90s and is a familiar view in urban and peri-urban areas including the capital Hargeisa. Large areas in and around Hargeisa have been completely invaded by $P$. juliflora, starting primarily from the river and expanding into bare lands and marginal areas.

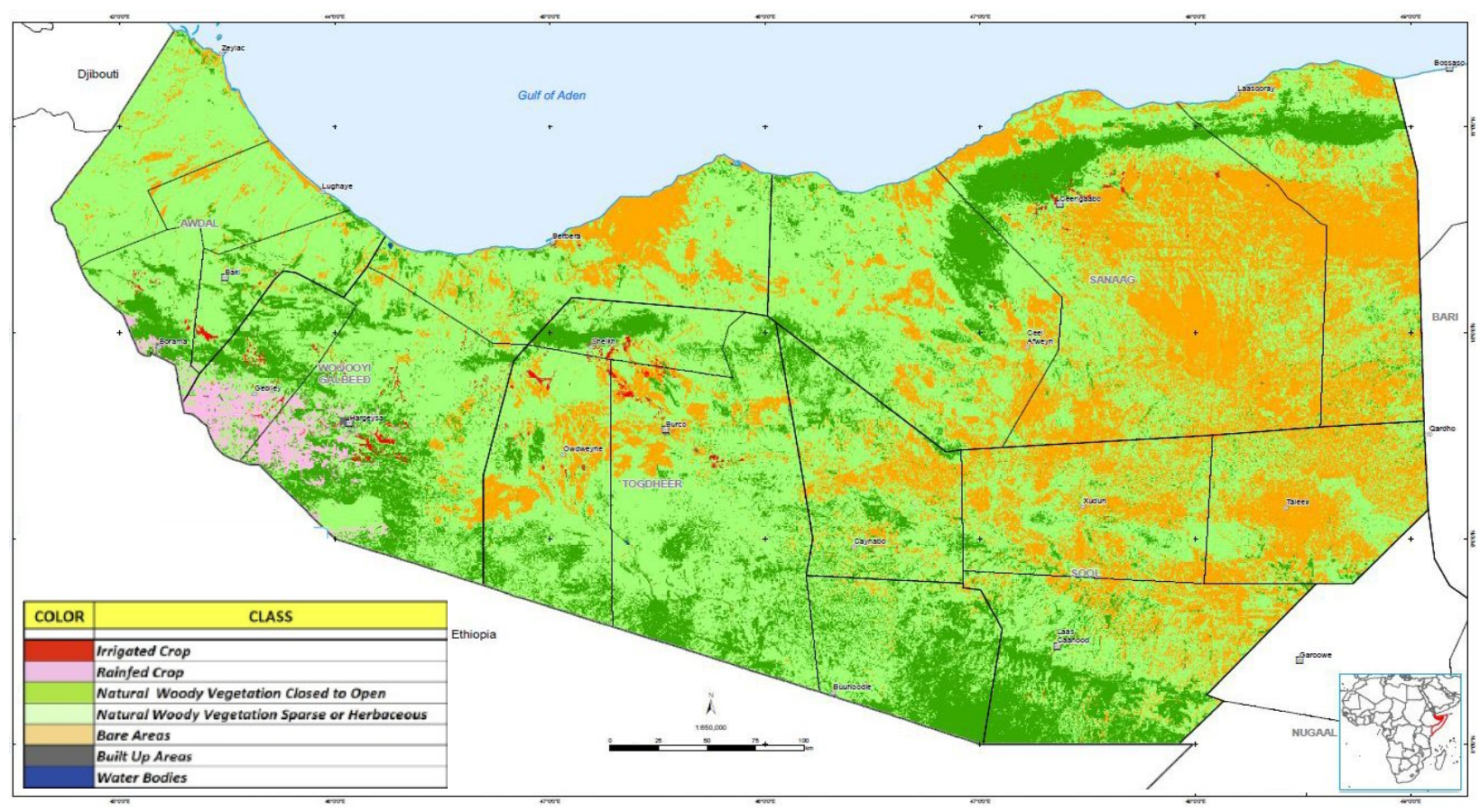

Figure 2. Land cover/land use map for Somaliland showing seven land cover classes. Rain-fed agricultural areas (pink are concentrated mainly in the Western part between Hargeisa and Borama, while irrigated agricultural areas are found in small patches depending on water availability from wells, water reservoirs and rivers. 


\section{DATA AND METHODS}

Data

$P$. juliflora trees and shrubs use water very efficiently due to their complex root system ${ }^{1}$. Consequently, $P$. juliflora outperforms most other tree species in terms of canopy water content and general plant vigour during dry periods ${ }^{15}$. To capture this trait, we concentrated on satellite imagery of the driest period in Somaliland, which is from January to end of March/early April (Figure 1). Eleven Landsat-8 scenes acquired between February and early April 2014 (Table 1) and covering the whole of Somaliland were downloaded from the USGS portal (http://earthexplorer.usgs.gov/). To correct for sun angle differences at different overpasses, the scenes were radiometrically calibrated and the Top of the Atmosphere (TOA) reflectance was computed. No atmospheric correction was applied considering that all images were acquired in the driest period of the year under mostly clear sky conditions.

Table 1. Landsat 8 scenes for February to April 2014 used in this study. The scenes cover entirely the whole area of Somaliland (ordered by path)

\begin{tabular}{cccc} 
Path/row & Acquisition date & $\begin{array}{c}\text { Cloud cover } \\
\mathbf{( \% )}\end{array}$ & $\begin{array}{c}\text { Sun elevation } \\
\text { angle (deg) }\end{array}$ \\
\hline $162 / 52$ & $20 / 03 / 2014$ & 3.29 & 55.13 \\
\hline $162 / 53$ & $20 / 03 / 2014$ & 0 & 55.75 \\
\hline $162 / 54$ & $20 / 03 / 2014$ & 0.02 & 56.34 \\
\hline $163 / 53$ & $20 / 03 / 2014$ & 0.01 & 61.05 \\
\hline $163 / 54$ & $20 / 03 / 2014$ & 0 & 61.29 \\
\hline $164 / 53$ & $23 / 02 / 2014$ & 11.26 & 55.29 \\
\hline $164 / 54$ & $23 / 02 / 2014$ & 0 & 55.90 \\
\hline $165 / 53$ & $02 / 03 / 2014$ & 6.77 & 56.94 \\
\hline $165 / 54$ & $02 / 03 / 2014$ & 0 & 57.46 \\
\hline $166 / 52$ & $10 / 04 / 2014$ & 3.08 & 64.58 \\
\hline $166 / 53$ & $10 / 04 / 2014$ & 2.36 & 64.47 \\
\hline
\end{tabular}

Although the canopy water content during the dry season is an important element for $P$. juliflora identification and was the main driver for the selection of dry season imagery, we decided not to focus only on vegetation indices (VIs) but to apply the supervised classification on all the spectral channels offered by Landsat- 8 . This follows a preliminary analysis performed by using vegetation indices only, which showed reduced accuracy with respect to the methodology retained. In fact, the NDII as well as other VIs like the NDVI and the normalized difference water index (NDWI) did not allow satisfactory separation of $P$. juliflora from other vegetation types, including other tree species and irrigated crops, which also maintain high canopy water content during dry periods. A classification method including the near totality of the Landsat 8 spectral information was found to be more adequate as short wave infrared bands containing information about water content are accompanied by the visible to near infrared bands related to specific leaf spectral signature and canopy density and structure. For the classification, the first seven bands plus NDVI were used, thus excluding the panchromatic, Cirrus and the thermal bands. The reasoning for including NDVI is to increase the separability of Prosopis based on the overall vegetation vigour.

Geo-referenced point data reporting $P$. juliflora presence were available from previous field campaigns carried out by SWALIM in 2013 and 2014. During such campaigns, primarily aimed at the collection of ground references for the production of the land use / land cover map of Figure 2, the presence of P. juliflora was visually detected on digital photos. On nearly 100 ground point photos $P$. juliflora could be recognized, but in most cases the ground site description did not allow precise understanding of its invasion severity and was rather following a criterion of "at least one $P$. 
juliflora plant visible somewhere in the picture". Only a small selection of the photos could therefore be retained for the definition of the training areas and the final number (around 30) was not sufficient for dividing them into training and testing data sets.

A limited VHR dataset was available for classification validation. These data included two windows acquired by Worldview2 in March 2014 of $33 \mathrm{~km}^{2}$ each, positioned North and North/West of Hargeisa (areas A1 and A2 in Figure 3). The data have a $50 \mathrm{~cm}$ resolution and true colour composites were made available to SWALIM under the NextView license.

\section{Classification}

Using the qualitative information about $P$. juliflora presence derived from the analysis of the digital photos described above together with the information about possible other land covers present at each site, we decided to define two classes only: one represented by Prosopis pure or mixed with natural tree vegetation, and one by Prosopis mixed with agriculture.

The first class includes pure P. juliflora areas with different degrees of soil coverage, ranging from a minimum of $15 \%$ to full coverage. Because of the difficulty of distinguishing completely pure $P$. juliflora from occurrences where it is mixed with different shrub or tree species, we included also mixed situations with natural vegetation. Since $P$. juliflora invades agricultural areas especially in the typical wadi agriculture systems of Somaliland, but also in rainfed areas, a separate class was made for Prosopis mixed with agriculture. Both classes present some difficulties in terms of spectral separability. Prosopis is in fact polymorphic and although sometimes pure or dominant, in most situations invades the habitat of other plants and thus mixes up with them in various forms, ranging from a a shrub to a fully developed tree. This classification represents thus a very broad discrimination only. Since not enough information was available for a full classification of the Landsat images, we decided to detect only those 2 Prosopis classes by using a classification scheme with probability thresholds. Pixels were thus considered as not infested if their probability of belonging to two classes was found to be lower than the set thresholds. For classification, the Maximum Likelihood Classifier was used with class specific thresholds of the probability to belong to the class. These thresholds were fixed empirically to 0.4 for the Prosopis pure or mixed with natural vegetation and to 0.5 for Prosopis mixed with agriculture. The higher the threshold value, the more spectrally similar the pixels are requested to be in order to be assigned to the corresponding class. The higher threshold value assigned to the agricultural mixed class reflects the fact that agriculture in the dry period is very heterogeneous and can span from bare areas in rainfed systems to green areas in irrigated systems. Lower thresholds would have thus lead to the inclusion of more bare soil and dense natural vegetation.

Most ground observations have been taken in an area corresponding to a single Landsat scene and consequently the classification training sites have been defined on one single Landsat scene (165/53). The other scenes have been classified by using the spectral signatures of the single scene containing the training sites. This is not ideal because spectral signatures are often area-specific and may change in space due to many factors (e.g. different soils, other species composition of the mixed classes, etc...) but complies with the logic of attempting a first detection trial over the whole of Somaliland.

After the classification, a slope mask was applied, masking out all areas with a slope larger than 2.2 degrees, based on SRTM90 data (http://www.cgiar-csi.org/data/srtm-90m-digital-elevation-database-v4-1). In this way, possible misclassifications in mountainous areas were reduced. Indeed, in mountainous terrain, shadows affecting either steep slopes and riverbeds or deep gullies often occur and lead to misclassifications. The masking also follows the logic that $P$. juliflora invasion normally starts along Wadis and riverbeds and affects mainly young soils such as fluvisols, regosols and calcisols. The threshold of 2.2 degrees was chosen in an empirical way, since the availability of information on $P$. juliflora invasion on different slopes terrain morphology as well as the soil data was not sufficient to perform a complete suitability analysis as done by Van den Berg et al. ${ }^{14}$ in South Africa.

\section{Validation of the classification}

Given the relatively small size of the ground points sample it was decided to retrieve the validation points on VHR imagery with a ground resolution of $50 \mathrm{~cm}$. A validation exercise was then performed for 200 randomly chosen points for each of the two areas covered by VHR imagery, acquired nearly at the same time of the Landsat data used for the classification. This follows a similar approach as used by Ayanu ${ }^{8}$ who referred to Google Earth imagery. This exercise 
does represent a preliminary check of the quality of our classification and cannot be considered a complete validation of the map.

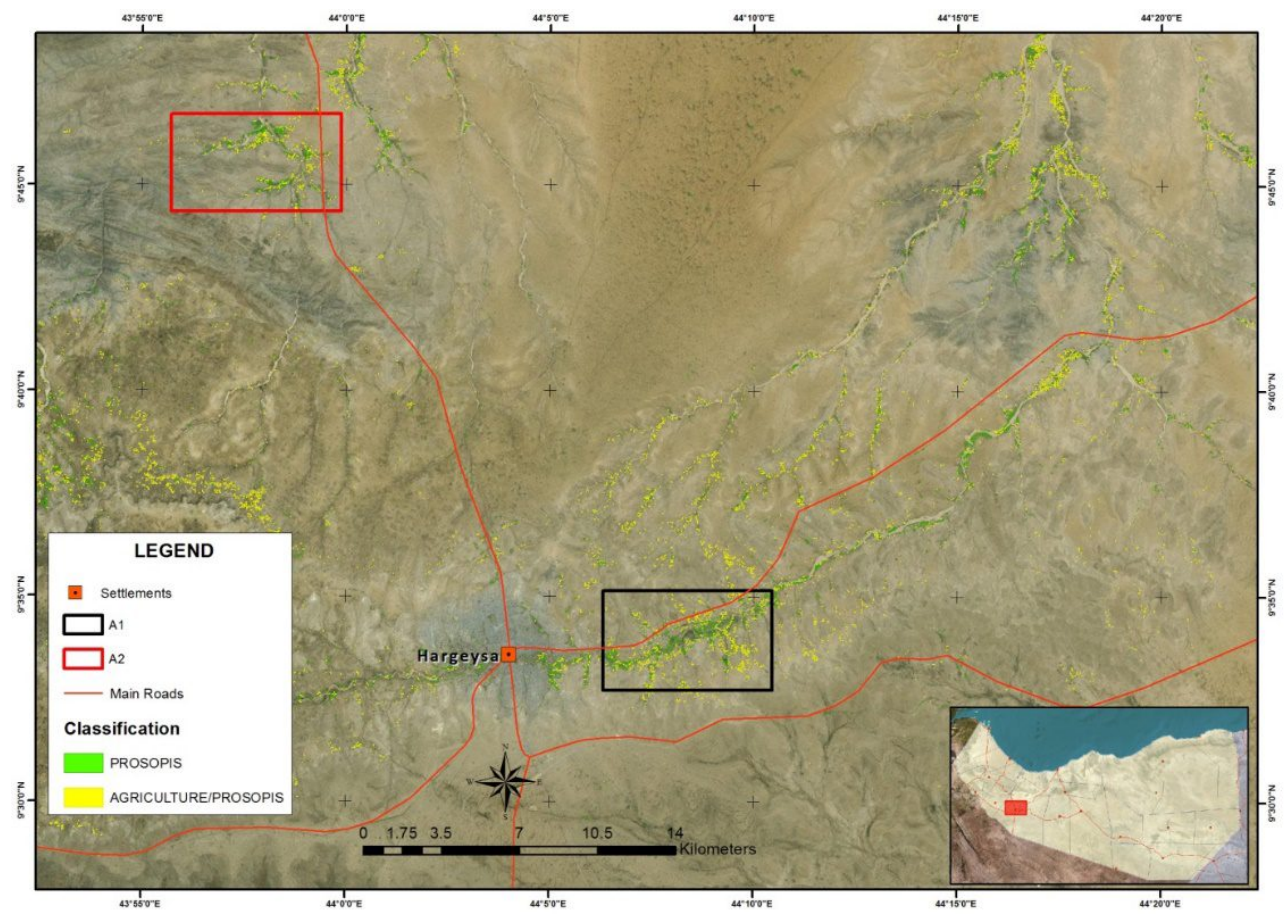

Figure 3. Areas invaded by Prosopis (green) and mixed with agriculture (yellow) around Hargeisa. The two outlined boxes show the validation areas on WorldView2 imagery. Validation area A1 (black box) and Validation area A2 (red box).

The VHR images cover areas with high $P$. juliflora presence in order to be representative, both for the Prosopis classes (class 1 and 2) and for the areas where the classifier did not find any Prosopis pixels ("no Prosopis"). In addition, the two validation areas (Figure 3) are ecologically different since one (A1) is a peri-urban area of Hargeisa and the other (A2) is a riverine agricultural area located about $25 \mathrm{~km}$ to the North East from Hargeisa. In order to reduce the dominance of the "no-Prosopis" class in the validation data set, a buffer of $60 \mathrm{~m}$ around all pixels classified as one of the two Prosopis classes was used for stratification of the random points. The 200 randomly extracted points were overlaid to the VHR imagery and visually interpreted. The results were then compared to the classification results in a classic confusion matrix. An example of the procedure is shown in Figure 4 and the two confusion matrices are included in tables 2 and 3. The overall accuracy is high $(>70 \%)$ but was not considered sufficient due to the dominance of the "no Prosopis" class. Kappa statistics should be less sensitive to this limitation and were calculated for both areas. There is a clear correspondence between the classified and visually interpreted areas, but the validation exercise also shows some of the main limitations of the approach (see section 5). 
Table 2. Confusion matrix for validation area A1 (a subset of this area is shown in figure 4).

\begin{tabular}{|c|c|c|c|c|}
\hline \multicolumn{2}{|r|}{ Area A1 } & \multicolumn{3}{|c|}{ Classfication } \\
\hline & & $\begin{array}{c}\text { Class 1: } \\
\text { Prosopis pure or } \\
\text { mixed with } \\
\text { natural tree } \\
\text { vegetation }\end{array}$ & $\begin{array}{c}\text { Class 2: } \\
\text { Prosopis mixed } \\
\text { with } \\
\text { agriculture }\end{array}$ & No Prosopis \\
\hline \multirow[t]{3}{*}{$\begin{array}{c}\text { Visual } \\
\text { interpretation }\end{array}$} & $\begin{array}{c}\text { Class 1: Prosopis pure or } \\
\text { mixed with natural tree } \\
\text { vegetation }\end{array}$ & 17 & 7 & 25 \\
\hline & $\begin{array}{c}\text { Class 2: Prosopis and } \\
\text { Agriculture }\end{array}$ & 4 & 8 & 6 \\
\hline & No Prosopis & 1 & 3 & 127 \\
\hline
\end{tabular}

Table 3. Confusion matrix for validation area A2.

\begin{tabular}{|c|c|c|c|c|}
\hline \multirow{2}{*}{\multicolumn{2}{|c|}{ Area A2 }} & \multicolumn{3}{|c|}{ Classfication } \\
\hline & & $\begin{array}{c}\text { Class 1: } \\
\text { Prosopis pure } \\
\text { or mixed with } \\
\text { natural tree } \\
\text { vegetation }\end{array}$ & $\begin{array}{l}\text { Class 2: } \\
\text { Prosopis mixed } \\
\text { with agriculture }\end{array}$ & No Prosopis \\
\hline \multirow[t]{3}{*}{$\begin{array}{c}\text { Visual } \\
\text { interpretation }\end{array}$} & $\begin{array}{c}\text { Class 1: Prosopis pure or } \\
\text { mixed with natural tree } \\
\text { vegetation }\end{array}$ & 18 & 6 & 16 \\
\hline & $\begin{array}{c}\text { Class 2: Prosopis mixed with } \\
\text { agriculture }\end{array}$ & 1 & 16 & 15 \\
\hline & No Prosopis & 0 & 6 & 120 \\
\hline \multicolumn{5}{|l|}{ Kappa $=0.53$} \\
\hline
\end{tabular}




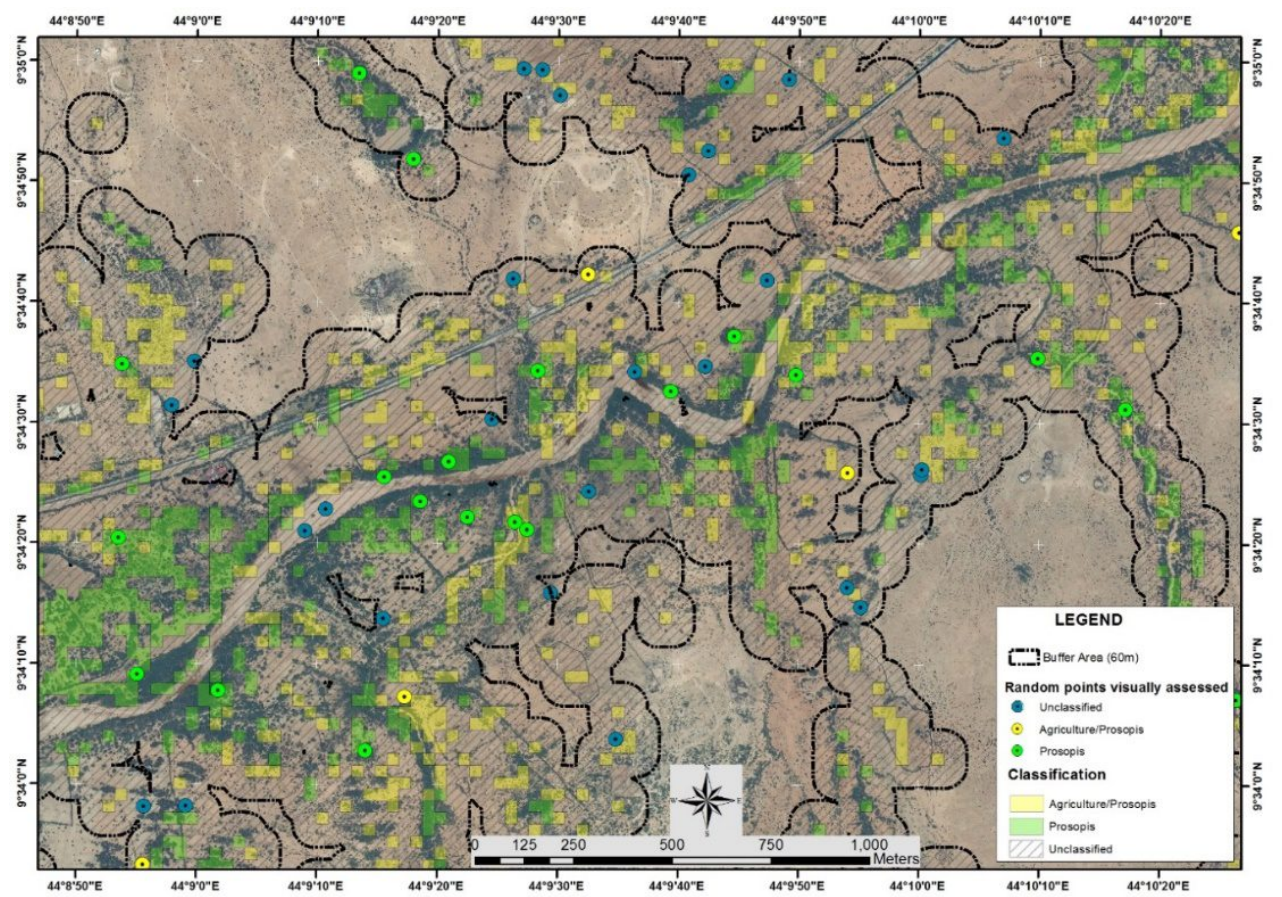

Figure 4: Subset of validation area A1. Random points located in a buffer area around classified Landsat- 8 pixels have been visually interpreted. P. juliflora points in green generally match green pixels of the Landsat Classification. The area also shows some difficulties, for example the definition of what is agricultural use and what not in such a dry area (some field borders are visible, but no crops during the dry season).

\section{RESULTS}

The image classification resulted in the map of $P$. juliflora infestation showing the distribution of the two classes across Somaliland. The extent covered by the two classes is $0.032 \%$ of the total area and is equally shared by the Prosopis pure or mixed with natural tree vegetation and by the Prosopis mixed with agriculture classes. This appears as a small percentage but does in fact represents a large area on the ground and in particular considering that large parts of Somaliland have little or no vegetation at all. 


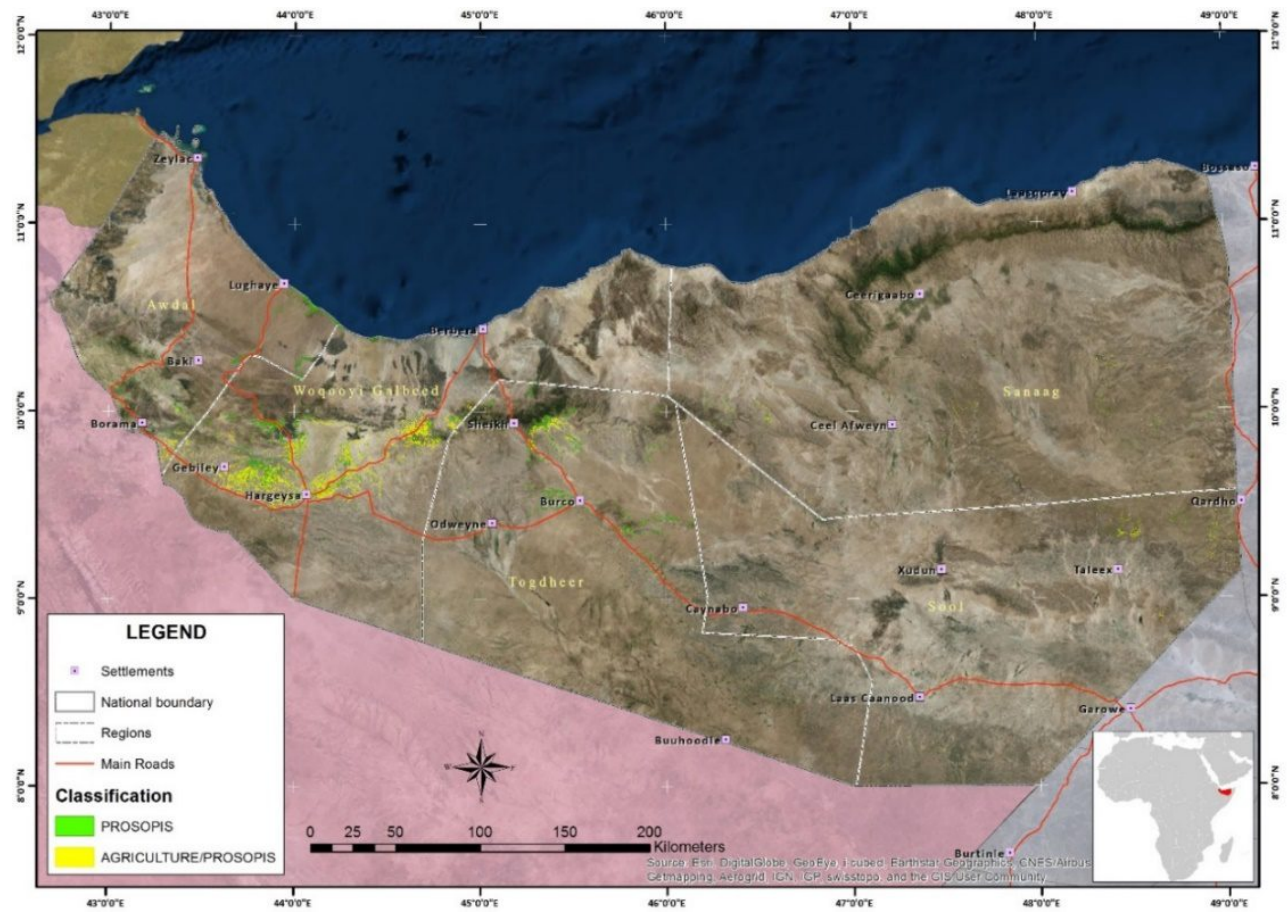

Figure 5. Somaliland with areas invaded by $P$. juliflora (green) and mixed with agriculture (yellow).

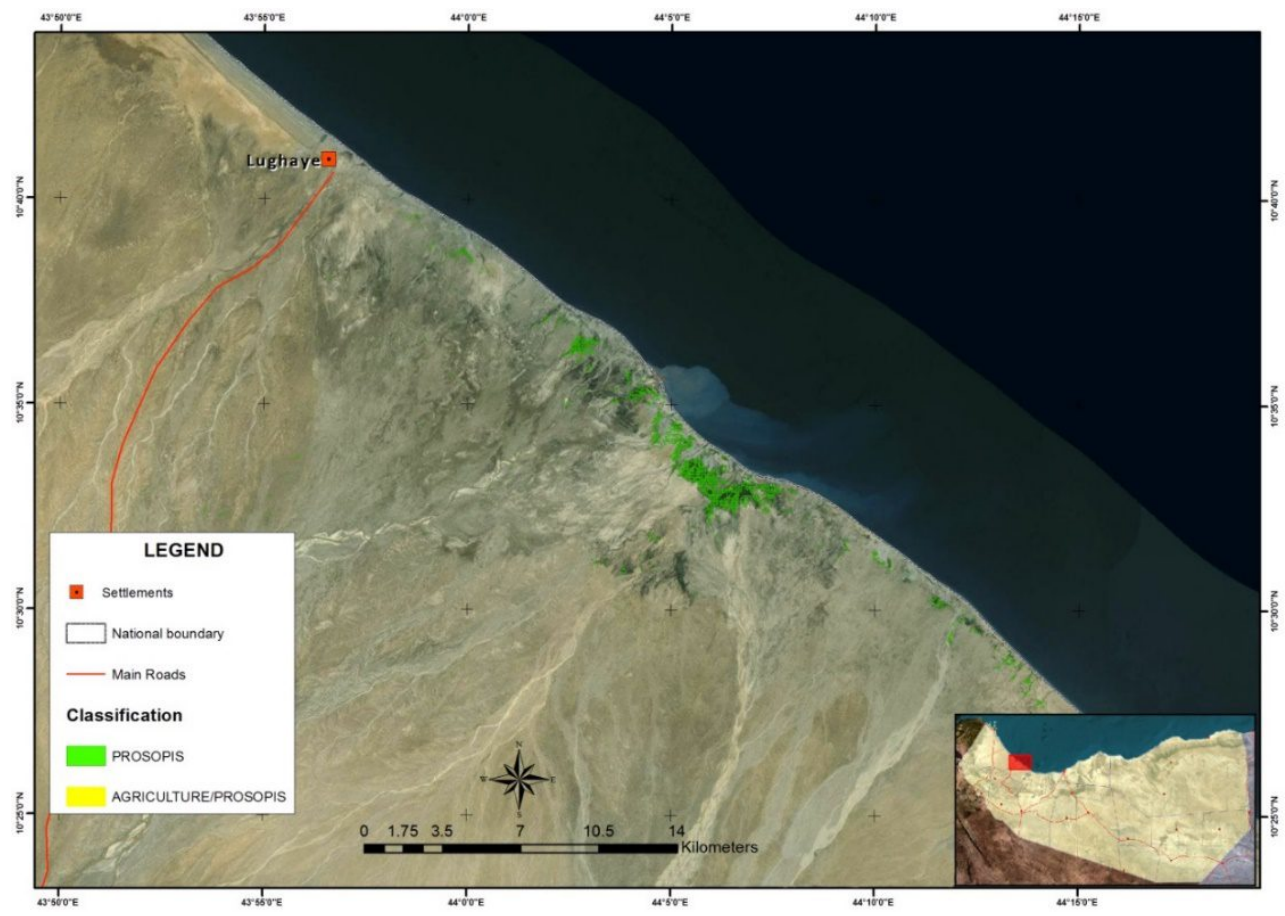

Figure 6. Areas invaded by P. juliflora (green) in Lughaye. 


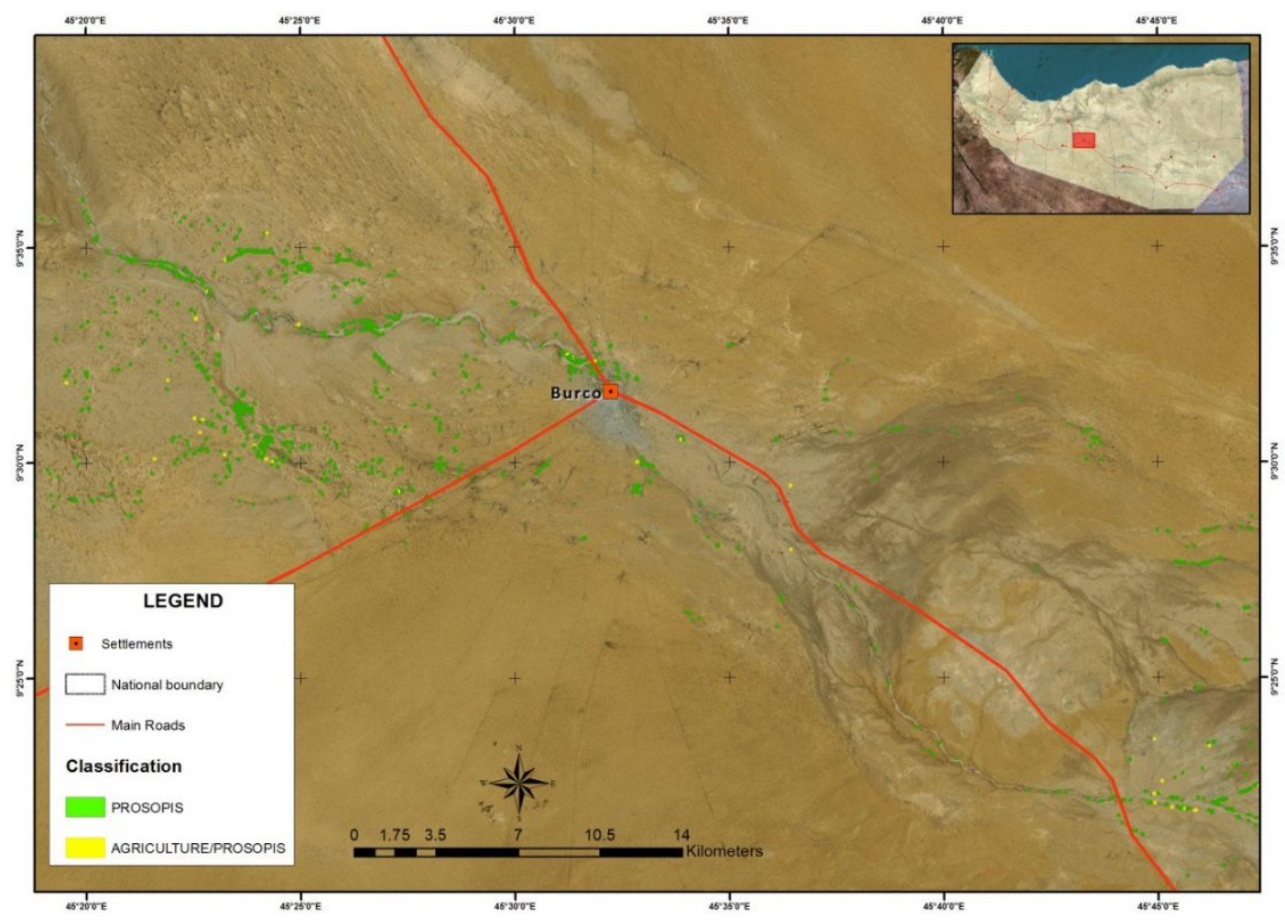

Figure 7. Areas invaded by P. juliflora (green) and mixed with agriculture (yellow) in Burco.

\section{DISCUSSION}

As expected, Prosopis was detected mainly along rivers, wadis and water bodies, as well as in urban and peri-urban areas, for both inland and coastal towns (Figure 5). Major expansion channels are the rivers in and North of Hargeisa, as well as some of the river deltas close to the Indian Ocean. Important roads such as the Hargeisa-Berbera road or the Hargeisa-Borama are also bordered by $P$. juliflora. Internal dry areas and plateaus, generally including very dry rain-fed agricultural areas are often less severely affected. These results confirm that in large areas of Somaliland, the invasive species competes directly with tree vegetation and irrigated agriculture for water and deep soils. The areas in proximity of wadis, water reservoirs and close to villages are the preferred areas of $P$. juliflora colonization. The Western part of the country shows a higher concentration with urban areas of Hargeisa, Burao and Odeweyne heavily infested as well as coastal areas between Lughaye and Berbera. P. juliflora is less commonly found in the South/Eastern dry areas and in the Sanaag plateau as compared to coastal and more agricultural areas. The results confirm other reports ${ }^{5,22}$ but thanks to the method applied here, the spreading could be mapped for the first time at $30 \mathrm{~m}$ spatial resolution and covering the whole territory of Somaliland (see disclaimer).

The relatively low accuracy of our classification suggests that $P$. juliflora is a difficult target to be mapped because of various factors, among others:

i) $\quad$. juliflora does often not occur as pure land cover class but is mixed either with other trees or shrubs or has partially invaded agricultural land. Pure P. juliflora can often be found in dense thickets along rivers and wadis, but these are most often too narrow belts to be mapped at Landsat resolution,

ii) $\quad$. juliflora is highly polymorphous depending on environmental conditions and is growing from large trees in deep soils with sufficient water to low semi-dry shrubs on very dry and stony soils,

iii) $\quad$. juliflora can invade agricultural areas, which in Somaliland range from irrigated tree plantations (e.g. citrus fruits) to semi-arid low density sorghum or millet fields so that the final and mixed reflectance can be very variable. 
The assumption that $P$. juliflora is able to tolerate drought period and it is thus spectrally distinguishable from other vegetated targets is only partially corroborated by this analysis since there was not enough ground information to map the tree in its pure cover but only in combination with other vegetation. However, in order to unambiguously determine if $P$. juliflora trees have a unique spectrum during the dry season, the collection of pure $P$. juliflora spectral signature with field spectrometers could be an important source of information.

All spectral signatures for the $P$. juliflora classes were collected from a single Landsat- 8 scene and then applied to the remaining ten scenes covering Somaliland. This was due to the fact that large parts of the country are still not fully accessible. Using training samples from a limited spatial extent probably reduces the accuracy of correct $P$. juliflora detection with a growing distance to the original training sites.

Finally, in some areas concentrated especially along the coast, even the dry season Landsat images, were partially cloud covered and there is evidence of some $P$. juliflora occurrence along the wadis and seasonal rivers which have not been detected because of the cloud cover.

\section{CONCLUSIONS AND POSSIBLE IMPROVEMENTS}

Landsat-8 images were found to be suitable for rapid $P$. juliflora mapping at the national scale and allowed the identification of $P$. juliflora in its typical habitats. In general the approach of classifying Landsat-8 imagery during the dry season proved to work well for a rapid identification of $P$. juliflora over large areas, as shown by the results and the validation exercise based on comparison with VHR imagery. Although there is room for methodological improvement and in particular for an improved ground data collection, the results confirm that $P$. juliflora is widely spread across Somaliland with a particularly high concentration in the Woqooyi Galbeed region. Also the pattern of invasion confirms that it invades first lowlands next to rivers and wadis as well as peri-urban areas both inland and along the coast. The mapping of $P$. juliflora as done in this work is an important piece of information in further understanding of agricultural and pastoral land degradation due to invasion of alien species in Somaliland and in similar environments across Eastern Africa. Such maps and the quantification of the areas occupied by this and similar species provide valuable reference information for alien species management and control plans and projects. At the same time it is also important to know the distribution of the plant for possible management and alternative uses projects. Charcoal production is a major driver of vegetation cover loss in Somaliland and Puntland ${ }^{21}$ and knowing how much P. juliflora is available and where, can inform $P$. juliflora management projects aiming at its use as pastoral resource or for charcoal production.

The proposed methodology could as well be used for multi-temporal classification, in order to monitor the progress of $P$. juliflora invasion over time. Visual analysis on VHR imagery such as available in Google Earth has also shown situations where $P$. juliflora has been cleared, for example in agricultural areas. This means that the $P$. juliflora map should not be considered as a static land cover layer, but only as a snapshot for early 2014 which is subject to further expansion or P. juliflora control measurements in some areas.

This analysis is preliminary to a more detailed mapping at local scale, which could take into consideration single plants and could make stronger use of shape and contextual patterns instead of spectral properties only. This would however require the use of very high resolution satellite image, not available for this study (with exception of the validation areas).

\section{ACKNOWLEDGEMENTS}

The Quickbird imagery was provided by the U.S. Department of State (USDS) Humanitarian Information Unit, under the NextView License. The ground photos have kindly been made available by FAO SWALIM.

\section{DISCLAIMER}

The authors and their respective organizations don't assume any responsibility for the geographic borders and names in this publication which are used for the purposes of orientation and mapping. 


\section{REFERENCES}

[1] Pasiecznik, N. M., The Prosopis juliflora - Prosopis pallida Complex: The Prosopis juliflora - Prosopis pallida Complex: A Monograph, HDRA Publishing, UK (2001).

[2] NAS., Firewood crops: Shrub and tree species for energy production, NAS, Washington D.C., USA (1980).

[3] Von Maydell, H. J., Trees and shrubs of the Sahel - their characteristics and uses, GTZ, Eschborn, Germany (1986).

[4] Zollner, D., "Sand dune stabilization in Central Somalia," For. Ecol. Manage. 16(1-4), 223-232 (1986).

[5] Awale, A. I.., Sugule, A. J., PROLIFERATION OF HONEY MESQUITE ( Prosopis juliflora ) in Somaliland: OPPORTUNITIES AND CHALLENGES CASE STUDY, CLHE, Abu Dhabi, UAE (2006).

[6] Tegegn, G., Experiences on Prosopis management case of Afar region, FARM-Africa, London(September), ARM-Africa, London (2008).

[7] Admasu, D., "Invasive plants and food security: the case of Prosopis juliflora in the Afar region of Ethiopia," FARM-Africa, IUCN(December), 1-13 (2008).

[8] Ayanu, Y., Jentsch, A., Müller-Mahn, D., Rettberg, S., Romankiewicz, C.., Koellner, T., "Ecosystem engineer unleashed: Prosopis juliflora threatening ecosystem services?," Reg. Environ. Chang. (2014).

[9] Mwangi, E.., Swallow, B., "Invasion of Prosopis juliflora and local livelihoods," 66 (2005).

[10] Dubow, A. Z., "Mapping and managing the spread of Prosopis Juliflora in Garissa County," Kenyatta Universtity, Kenya (2011).

[11] Obiri, J. F., "Invasive plant species and their disaster-effects in dry tropical forests and rangelands of Kenya and Tanzania," J. Disaster Risk Stud. 3(2), 417-428 (2011).

[12] Dubale, A., "Impacts of Prosopis juliflora invasion and control using charcoal production in Afar National Regional State, Ethiopia," University of Wales, Bangor, UK (2006).

[13] Fourie, F., Mbatha, K., Verster, H.., van Dyk, G., "The Effect of Vegetation ( Prosopis Sp .) on Groundwater levels in Rugseer, Kenhardt, South Africa" (2002).

[14] Van de Berg, E. C., Kotze, I.., Beukes, H., "Detection, Quantification and Monitoring of Prosopis in the Northern Cape Province of South Africa using Remote Sensing and," South African J. Geomatics 2(2), 68-81 (2013).

[15] Hoshino, B., Karamalla, A., Abd Elbasit, M., Manayeva, K., Yoda, K., Suliman, M., Elgamri, M., Nawata, H.., Yasuda, H., "Evaluating the Invasion Strategic of Mesquite ( Prosopis juliflora ) in Eastern Sudan Using Remotely Sensed Technique," J. Arid L. Stud. 4, 1-4 (2012).

[16] Mohamed, A. H., Holechek, J. L., Bailey, D. W., Campbell, C. L.., DeMers, M. N., "Mesquite encroachment impact on southern New Mexico rangelands: remote sensing and geographic information systems approach,” J. Appl. Remote Sens. 5(1), 053514 (2011).

[17] Mirik, M.., Ansley, R. J., "Comparison of Ground-Measured and Image-Classified Mesquite (Prosopis glandulosa) Canopy Cover," Rangel. Ecol. Manag. 65(1), 85-95 (2012).

[18] [19] Balint, Z., Paron, P.., Alim, M., Atlas of Somali Water and Land Resources, FAO-SWALIM, Nairobi, Kenya (2009).

[20] Oroda, A. S., Oduori, S. M.., Vargas, R. R., "Application of Remote Sensing Techniques for the Assessment of Pastoral Resources in Puntland, Somalia" (2007).

[21] Oduori, S. M., Rembold, F., Abdulle, O. H.., Vargas, R., "Assessment of charcoal driven deforestation rates in a fragile rangeland environment in North Eastern Somalia using very high resolution imagery," J. Arid Environ. 75(11), 1173-1181, Elsevier Ltd (2011).

[22] IFAD., PENHA., "Exploring Prosopis Management and Policy Options in the Greater Horn of Africa," 2015, PENHA, London. 